\title{
The order of presentation of conditioned stimuli during extinction
}

\author{
RALPH W. RICHARDS and DAVID M. SARGENT \\ Colorado State University, Fort Collins, Colorado
}

\begin{abstract}
Three experiments examined the effects of prior extinction with nontarget CSs on a target CS's rate of extinction and amount of associative loss. After fear was conditioned to several CSs, rats received extinction training with the target CS either before or after extinction with nontarget CSs. In general, neither rate of extinction nor amount of associative change, as measured by reinstatement and relearning, were significantly affected by order of extinction. The present results do not support Rescorla's interpretation of extinction.
\end{abstract}

Since the early 1970 s, it has become increasingly common to find classical conditioning described in terms of an associative connection between memorial representations of the conditioned stimulus (CS) and the unconditioned stimulus (US) (Domjan \& Burkhard, 1982; Holland \& Rescorla, 1975; Rescorla, 1973a, 1973b, 1974, 1978; Wagner, 1976, 1978, 1981; Whitlow, 1976). In this view, an effective CS retrieves or arouses the US representation, and the potency of the latter determines the magnitude of the conditioned response (CR). The effects of various postconditioning manipulations (e.g., delivering a more or a less intense US during USonly trials; Holland \& Rescorla, 1975; Rescorla, 1974) imply that the CR is dependent upon the current potency of the US representation.

Rescorla and Heth (1975) suggested that loss of the CR during extinction occurs in part because delivery of the CS without the US weakens or degrades the potency of the memorial representation of the US. In support of this suggestion, they produced recovery of an extinguished CR merely by delivering the US. This so-called reinstatement effect purportedly occurred because some associative strength survived extinction and because the postextinction presentations of the US assured that a strong US representation would be aroused when the CS was again presented. Rescorla and Cunningham (1978) further suggested that a weakening of the US representation actually prevents associative loss; that is, the magnitude of associative loss is supposed to be directly related to the potency of the US representation aroused on that extinction trial.

According to the above analysis, it should be possible to alter extinction with one CS by first pro-

Reprints may be obtained from Bill Richards, Department of Psychology, Colorado State University, Fort Collins, Colorado 80523. This research was sponsored in part by NIMH Grant 5-R01-MH3094. viding extinction to other CSs. Specifically, prior extinction should assure a weak US representation when extinction with the target CS begins, and this should accelerate the decrease in the CR, but retard the loss in associative strength. The present experiments tested these predictions.

\section{EXPERIMENT 1}

\section{Method}

Subjects. Twenty-four experimentally naive, male, SpragueDawley rats (3-4 months of age at the outset) were maintained at approximately $80 \%$ of their free-feeding weights.

Apparatus. The eight single-lever chambers (Gerbrands, Model C; internal dimensions: $19.4 \times 20.3 \times 23.2 \mathrm{~cm}$ ) were enclosed in separate chests that contained a houselight (6 W, 62.6 V from a Variac) on the rear wall. Electric shocks were delivered to the grid floors by Lafayette Instruments shockers (Models 5280) and scramblers (Models 82400). A tone of approximately $1000 \mathrm{~Hz}$, produced by the medium setting of a Behavior Systems International tone generator (Model 531), was delivered through a speaker mounted near the food magazine.

Procedure. After barpressing was established with continuous reinforcement, a variable-interval (VI) 2-min schedule was gradually introduced. All subsequent sessions employed the VI 2 -min schedule and were $2 \mathrm{~h}$ in duration. The reinforcer was always a standard $45-\mathrm{mg}$ Noyes food pellet.

After five sessions with the VI 2-min schedule, the rats received five conditioning sessions that contained two tone-shock pairings and two houselight-shock pairings. Onset of the .5-sec, .5-mA shock always coincided with the offset of the 2-min CSs.

The rats were then assigned to three equal-sized groups and given 12 sessions of fear extinction with six CS-only trials per session. The tone $(T)$ and houselight $(H)$ were presented during the first and last six sessions, respectively, for rats in Group TH; the order was reversed for rats in Group HT. Rats in Group T/H received three $T$ and three $H$ trials in mixed order during each session. Extinction was followed by a pretest session in which $T$ was presented three times, a session with four unsignaled shocks (.5 sec, $.5 \mathrm{~mA})$, and a test session in which $T$ was presented twice.

\section{Results}

The magnitude of suppression produced by the CSs was measured by the standard suppression ratio, 
$X /(X+Y)$, where $X$ represents the response rate during the $C S$, and $Y$, the response rate during a comparable interval just prior to $C S$ onset. The upper portion of Figure 1 shows that the houselight produced nearly complete suppression at the end of conditioning (Panel A) and that this suppression gradually disappeared during extinction (Panel B). Since rats in Group $\mathrm{T} / \mathrm{H}$ received only three houselights per extinction session, data from their successive extinction sessions were combined so that all data points during extinction would represent six trials. A 3 (groups) $\times 6$ (blocks of extinction trials) analysis of variance indicated that the decrease in suppression was significant [blocks, $F(5,105)=$ $91.28, \mathrm{p}<.05]$, but that any suggestive differences between the groups were not reliable [groups, $F(2,21)$ $=1.11, p>.05$; groups $\times$ blocks, $F(10,105)=1.23$, $\mathrm{p}>$.05].

The upper portion of Table 1 contains the mean response rates that occurred in the pre-CS intervals (i.e., the Ys in the SR formula) during extinction sessions with the houselight. Rats that received extinction with the tone first (Group TH) frequently showed higher prehouselight rates than did rats in the other groups. A two-way analysis of variance yielded nonsignificant main effects for groups $[F(2,21)=1.39, p>.05]$ and blocks $[F(5,105)=$
1.78, $\mathrm{p}>.05]$, but a significant groups $\times$ blocks interaction $[F(10,105)=2.36, p<.05]$. Dunn tests were used to make separate pairwise comparisons for each block; brackets in Table 1 indicate differences that were found to be significant.

Panels A and B in the lower portion of Figure 1 show that the nearly complete suppression produced by the tone at the end of conditioning gradually disappeared during extinction. Moreover, extinction seemed to occur somewhat more rapidly for rats that had first received extinction with the houselight. A two-way analysis of variance revealed a nonsignificant groups effect $[F(2,21)=1.75, p>.05]$, a clearly significant blocks effect $[F(5,105)=68.51$, $\mathrm{p}<.05$ ], and a barely significant groups $\times$ blocks interaction $[F(10,105)=1.97, p \approx .05]$. When separate Dunn tests were used to compare the groups' suppression ratios within each block, only the following comparisons were found to be significant (p <.05): Block 1, HT vs. TH; Block 2 , HT vs. TH and HT vs. T/H. The lower portion of Table 1 shows that rats with prior extinction to the houselight (Group HT) maintained higher pretone response rates early in extinction. A two-way analysis of variance yielded a significant blocks effect $[F(5,105)=4.35, p<.05]$, a significant groups $\times$ blocks interaction $[F(10,105)=4.26, p<.05]$, and

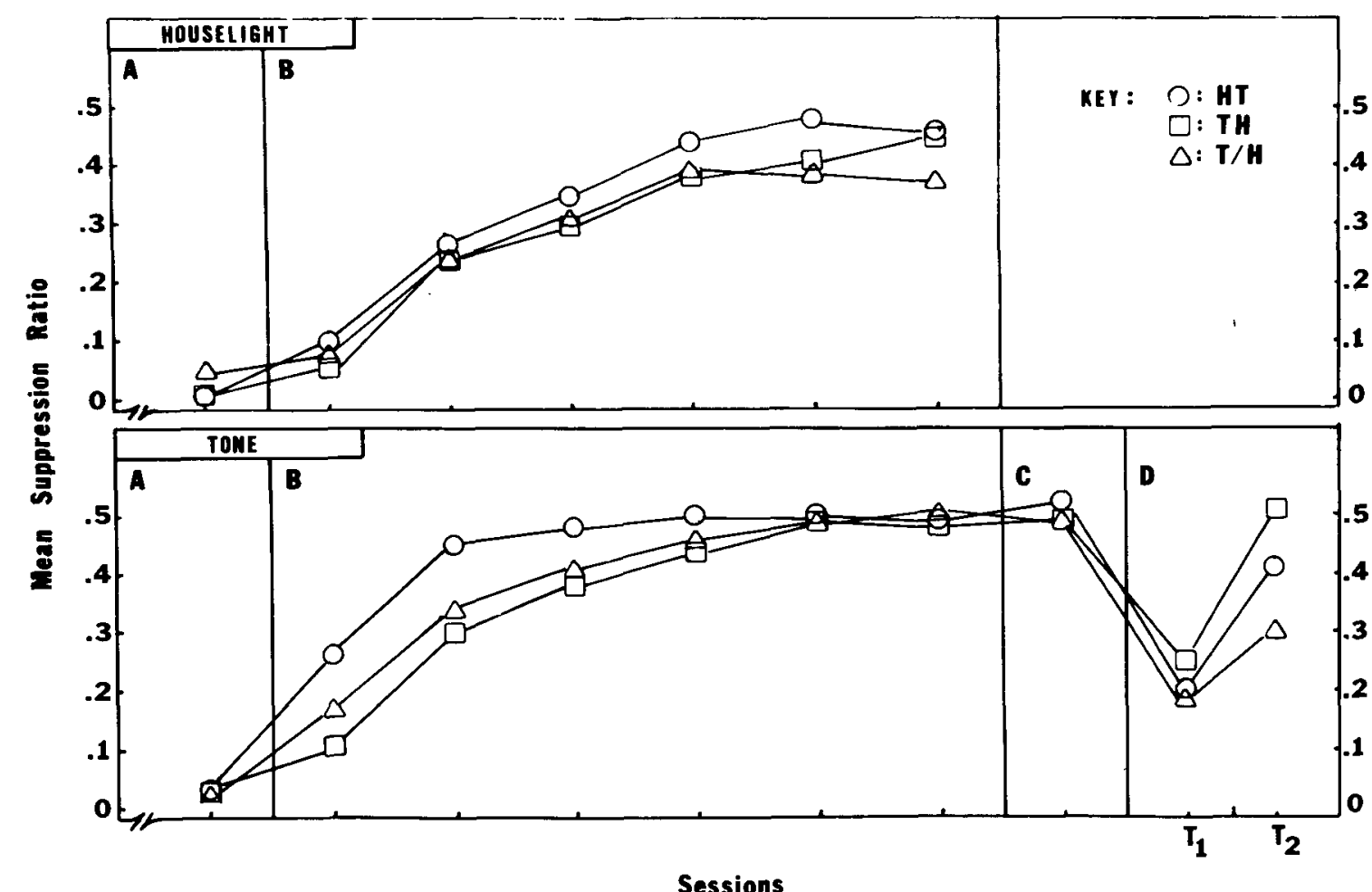

Figure 1. Mean suppression ratios during houselight (upper portion) and tone (lower portion) for rats in Groups TH (squares), HT (circles), and T/H (triangles). Panel A represents the last day of conditioning, Panel B successive blocks of six extinction trials, Panel $C$ the pretest, and Panel $D$ the two test trials. 
Table 1

Mean Responses per Minute in Prehouselight and Pretone Intervals During Each Extinction Session

\begin{tabular}{|c|c|c|c|c|c|c|}
\hline $\begin{array}{c}\text { Session/ } \\
\text { Group }\end{array}$ & 1 & 2 & 3 & 4 & 5 & 6 \\
\hline & \multicolumn{6}{|c|}{ Houselight } \\
\hline $\begin{array}{l}\mathrm{HT} \\
\mathrm{TH} \\
\mathrm{T} / \mathrm{H}\end{array}$ & $=\left[\begin{array}{l}12 \\
22 \\
13\end{array}\right.$ & {$\left[\begin{array}{l}16 \\
22 \\
17\end{array}\right.$} & $\begin{array}{r}{\left[\begin{array}{l}15 \\
20 \\
16\end{array}\right.}\end{array}$ & $\begin{array}{l}17 \\
21 \\
17\end{array}$ & {$\left[\begin{array}{r}19 \\
{\left[\begin{array}{l}21 \\
13\end{array}\right.}\end{array}\right.$} & $\begin{array}{l}17 \\
16 \\
16\end{array}$ \\
\hline & \multicolumn{6}{|c|}{ Tone } \\
\hline $\begin{array}{l}\text { HT } \\
\text { TH } \\
\text { T/H }\end{array}$ & {$\left[\begin{array}{l}1 \\
1 \\
13 \\
12\end{array}\right.$} & $\begin{array}{l}17 \\
16 \\
16\end{array}$ & $\begin{array}{l}19 \\
18 \\
17\end{array}$ & $\begin{array}{l}16 \\
19 \\
16\end{array}$ & {$\left[\begin{array}{r}20 \\
21 \\
14\end{array}\right.$} & {$\left[\begin{array}{l}20 \\
16 \\
14\end{array}\right.$} \\
\hline
\end{tabular}

a nonsignificant groups effect $[F(2,21)=.51, p>$ $.05]$; the brackets in the table again indicate the within-session comparisons that were found significant by Dunn tests.

Panel $\mathrm{C}$ in Figure 1 shows that little suppression occurred during the tone in the pretest administered after the extinction phase. However, after a session with four unsignaled shocks, substantial suppression did occur when the tone was next presented $\left(T_{1}\right.$ in Panel D). For each group, the increase in suppression was significant $[\operatorname{ts}(7) \geqslant 3.79, p<.05]$; however, there was no significant difference among the groups' SRs on $T_{1}[F(2,21)=.31, p>.05]$. Only rats in Group $\mathrm{T} / \mathrm{H}$ continued to show significantly more suppression on the second test trial $\left(T_{2}\right.$ in Panel D) than in the pretest $[t(7)=2.83, p<.05]$. The difference between the groups' $T_{2}$ SRs was found to be significant by a one-way analysis of variance $[F(2,21)=3.98, p<.05]$. In terms of pretone response rates, separate one-way analyses of variance showed no significant differences between Groups $H T, T H$, and $T / H$ during the pretest $[17,23$, and 17 responses $/ \mathrm{min}$, respectively; $F(2,21)=1.18$, $\mathrm{p}>.05]$, Test Trial $1[18,17$, and $15 ; \mathrm{F}(2,21)=$ $.16, p>.05]$, or Test Trial $2[19,18$, and $17 ; F(2,21)$ $=.05, \mathrm{p}>.05]$. Separate $t$ tests also failed to reveal any significant changes in pre-CS rates from pretest to Test Trial 1 [ts(7) $\leqslant 1.20, \mathrm{p}>.05]$ or to Test Trial $2[\operatorname{ts}(7) \leqslant 1.01, \mathrm{p}>.05]$.

\section{Discussion}

Although extinction of fear during the tone occurred more rapidly when preceded by extinction with the houselight, extinction during the houselight did not occur more rapidly when preceded by extinction with the tone. Since fruitful discussion of this discrepancy presupposes both findings' reliability, and since the former effect only barely reached an acceptable level of significance, it seemed prudent to examine the reliability of the facilitation of extinction during the tone. Accordingly, two additional experiments were conducted.
The present experiment obtained a reinstatement effect (cf. Rescorla \& Heth, 1975; Rescorla \& Cunningham, 1978), and did so after a much greater number of extinction trials (36) than employed previously. The generally rapid disappearance of the CR in testing also agrees with Rescorla's work. More importantly, a larger reinstatement effect was not obtained when extinction with the target CS occurred last, as Rescorla's "rules of associative change" suggest. However, since the present procedure may not have been optimal for producing and/or detecting different amounts of associative loss, additional research seemed warranted.

\section{EXPERIMENT 2}

The present experiment had two goals: (1) to assess the reliability of the previous finding that extinction of fear during the tone was facilitated by prior extinction with another CS and (2) to demonstrate different amounts of extinction-induced loss in the tone's associative strength. Towards these ends, several procedural changes were initiated. First, subjects received extinction with the tone either before or after extinction with two other CSs. Within the theoretical framework employed by Rescorla to account for extinction, it seemed possible that prior extinction with two nontarget CSs might assure an especially weak US representation when extinction to the tone began. However, if extinction with the first nontarget CS fully degrades the US memory, extinction with the second nontarget CS would be expected, at worst, to have no effect. Because of equipment limitations, two visual stimuli were chosen as the nontarget CSs. Although substantial generalization between these visual stimuli was expected, it seemed unlikely that this would decrease the likelihood of obtaining an order-ofextinction effect with the tone. As a second procedural change, the number of reinstatement shocks was reduced. It was expected that fewer shocks would decrease the magnitude of the reinstatement effects and increase the likelihood of obtaining a difference between the groups. Finally, a relearning test was included to obtain more extensive measures on the loss in the tone's associative strength during extinction.

\section{Method}

Subjects. Sixteen experimentally naive rats like those in Experiment 1 were employed.

Apparntus. Except for occasional illumination of an 1820 light bulb $(7.6 \mathrm{~V})$ mounted behind a red lens cap near the lever, the apparatus was identical to that in Experiment 1.

Procedure. After preliminary training and five sessions of VI 2-min training, rats received five fear-conditioning sessions. Each conditioning session contained two pairings of a 2-min tone, a 2-min red pilot light, and a 2 -min houselight with shock. 
All rats then received six extinction trials per day for the next 15 sessions. For half of the rats (Group TPH), fear during the tone, pilot light, and houselight was extinguished in the first, second, and third blocks of five sessions, respectively; for the other half (Group HPT), the ordering of the CSs was reversed.

All rats then received two sessions of VI-only training, two pretest sessions (two tones/session), and one session with two unsignaled shocks. Each of the final eight sessions contained two tone-shock pairings with a 2 -min delay between tone offset and shock onset for the first five sessions and a 30 -sec delay for the last three sessions; since data were recorded separately for each trial in the first session and since the very first trial provided a test for reinstatement, the first of these sessions will be referred to as the test session and the remaining seven sessions will be referred to as relearning sessions.

Except as noted above, the procedure was identical to that of the previous experiment.

\section{Results}

Since major concern was with extinction of fear during the tone and since the expected generalization between the two visual CSs apparently did occur, only tone SRs are presented. Panels A and B in Figure 2 show that the nearly complete suppression produced by the tone at the end of conditioning gradually disappeared during the extinction sessions. Most importantly, extinction with the tone was not facilitated by prior extinctions with the visual CSs. A two-way analysis of variance revealed a significant sessions effect $[F(4,56)=22.55$, p $<$ $.05]$, but a nonsignificant group effect $[F(1,14)=$ $.58, \mathrm{p}>.05]$ and a nonsignificant groups $\times$ sessions interaction $[F(4,56)=1.15, p>.05]$. Table 2 presents mean response rates prior to the tone during each extinction session. Large differences between the groups were apparent on only the third and fifth sessions. Statistical analysis by a two-way analysis of variance [groups, $F(1,14)=.44, p>.05$; sessions, $F(4,56)=2.22$, $p<.05$; groups $x$ sessions, $F(4,56)=6.45, p<.05$ ] and Dunn tests revealed that the differences between the groups' pre-CS rates were significant $(p<.05)$ for only Extinction Sessions 3 and 5.

Panel C in Figure 2 shows that the tone produced no suppression during the pretest. Panel D indicates a slight, but nonsignificant [ts $(7) \leqslant 1.78, p>.05]$, drop in SRs on the first trial $\left(T_{1}\right)$ of the test sessionno reinstatement effect was obtained. Finally, Panel E shows that suppression did develop during the relearning sessions, but again no significant difference between the groups was obtained [groups, $\mathrm{F}(1,14)=.42, \mathrm{p}>.05$; sessions, $\mathrm{F}(6,84)=3.31$, $\mathrm{p}<.05$; groups $\times$ sessions, $F(6,84)=.90, p>.05]$. The mean pretone response rates for rats in Group HPT during the final pretest session, Test Trial 1 , Test Trial 2, and the seven relearning sessions were, in order, 14, 15, 11, 15, 11, 14, 9,11, 8, and 9 . The corresponding rates for rats in Group TPH were $10,13,9,11,9,9,12,11,8$, and 12. Separate dependent $t$ tests failed to reveal any significant changes in either groups' pretone response rates from pretest to Test Trial 1 [ts(7) $\leqslant 1.15, p>.05]$ or to Test Trial 2 [ts $(7) \leqslant 1.73, p>.05]$. Separate independent $t$ tests showed that rats in Group HPT responded at a significantly higher rate during the pretone interval of the pretest $[t(14)=2.08, p<.05]$, but that there were no significant group differences on Test Trial 1 [ $\mathrm{t}(14)=.49, \mathrm{p}>.05]$ or Test Trial 2 $[t(14)=.67, p>.05]$. A two-way analysis of vari-

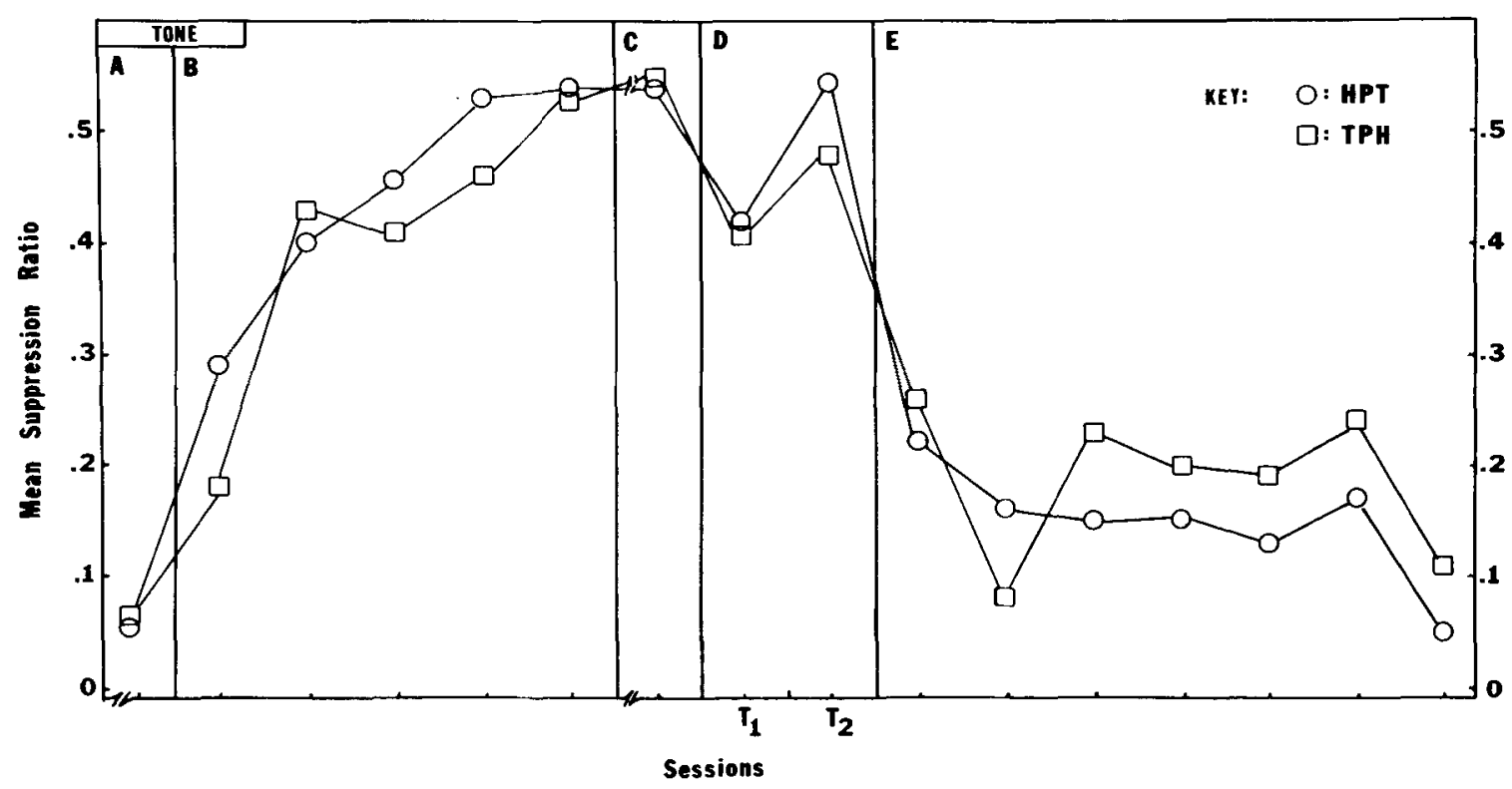

Figure 2. Mean suppression ratios during tone for rats in Group TPH (squares) and Group HPT (circles). Panel A represents the last day of conditioning. Panel B successive days of extinction, Panel C the pretest, Panel D the two test trials, and Panel $E$ the relearning sessions. 
Table 2

Mean Responses per Minute in Pretone Intervals During Each Extinction Session

\begin{tabular}{|c|c|c|c|c|c|}
\hline $\begin{array}{c}\text { Session/ } \\
\text { Group }\end{array}$ & 1 & 2 & 3 & 4 & 5 \\
\hline HPT & 14 & 12 & $\Gamma 15$ & 14 & $\Gamma 18$ \\
\hline TPH & 13 & 14 & $L_{11}$ & 13 & $L_{12}$ \\
\hline
\end{tabular}

ance on pretone rates during the relearning phase yielded a nonsignificant groups effect $[F(1,14)=$ $.09, \mathrm{p}>.05$ ] but significant effects for Sessions $[F(6,84)=2.66, p<.05]$ and for the groups $\times$ sessions interaction $[F(6,84)=2.60, p<.05]$; however, Dunn tests failed to reveal any significant differences when the groups' rates for corresponding sessions were compared.

\section{Discussion}

Extinction of fear during the tone was not significantly faster following extinction with the other CSs. This result conflicts with Experiment 1's marginally significant effect (even though changes were made to increase the effect's magnitude), but agrees with Experiment 1's failure to obtain accelerated extinction with the houselight after extinction with the tone.

Fear during the tone did not reappear after two unsignaled shocks were delivered. Although the procedures in Experiments 1 and 2 differed in several ways, the fewer unsignaled shocks given here was probably critical. Finally, the rate of relearning indicated that the order of extinction did not alter loss in associative strength.

\section{EXPERIMENT 3}

In a final attempt to produce an order-of-extinction effect, further modifications were made in the experimental procedure. A major concern was with retarding the purported degradation in the US representation for subjects receiving extinction with the target CS first; perhaps between-group differences did not appear previously because the US representation had weakened too quickly for these subjects. Towards this end, the number of conditioning trials was increased, the US intensity was increased, and the number of daily extinction trials with the target CS was reduced. Fewer total extinction trials with the target CS were also provided. Another goal was to increase the sensitivity of the measurement techniques. Thus, the number of rats per group was doubled and data were collected separately for each extinction trial. Associative loss was again measured following four unsignaled USs and during a brief relearning phase.

\section{Method}

Subjects. Thirty-two rats like those in the previous experiments were used.

Apparatus. The apparatus was the same as in Experiment 2.

Procedure. After seven fear conditioning sessions with $0.5-\mathrm{mA}$ shock and three sessions with $1.0-\mathrm{mA}$ shock, half of the rats (Group TPH) received five extinction sessions with the tone (two trials/session), followed by four extinction sessions with the pilot light (six trials/session) and four extinction sessions with the houselight (six trials/session). The order of CS presentation during extinction was reversed for the other half of the rats (Group HPT). All rats then received two pretest sessions (one tone/session), one session with four unsignaled .5-sec, 1-mA shocks, and a final test session. The test session contained four tone-shock trials in which the $1.0-\mathrm{mA}$ shock was delivered $30 \mathrm{sec}$ after offset of the tone.

Except as noted above, the procedure was identical to that of Experiment 2.

\section{Results}

Figure 3 shows that rats in both groups evidenced strong suppression during the tone at the end of conditioning (Panel A) and that this suppression gradually disappeared across the 10 trials of extinction (Panel B). Statistical analysis revealed that the loss of suppression was significant [trials, $F(9,270)=32.12, p<.05]$ but that there was no significant difference between the groups [groups, $F(1,30)=.51, p>.05 ;$ groups $\times$ trials, $F(9,270)=$ $1.62, \mathrm{p}>.05]$. Table 3 shows the mean response rates in the pretone intervals for each extinction trial. A 2 (groups) $\times 10$ (trials) analysis of variance yielded a significant trials effect $[F(9,270)=2.39$, $\mathrm{p}<.05$ ] but nonsignificant effects for groups $[F(1,30)=2.82, p>.05]$ and for the groups $\times$ trials interaction $[F(9,270)=1.56, p>.05]$.

Figure 3 also shows that the tone produced little suppression during the pretest (Panel $\mathrm{C}$ ), but much suppression after delivery of four unsignaled shocks (first trial in Panel D). The increase was significant for rats in both groups [ts $(15) \geqslant 6.06, p<.05$ ]; however, there was no significant difference between the groups' SRs on this trial [t(15) $=.14, \mathrm{p}>.05]$. Finally, suppression was maintained across the remaining relearning trials without any significant differences between the groups [groups, $\mathbf{F}(1,30)=$ .29 , $p>.05$; trials, $F(3,90)=.28$, p > .05; groups $x$ trials, $F(3,90)=.18, p>.05]$. The mean response rates in the pretone intervals for rats in Group HPT during the last pretest session and each relearning trial were, in order, $13,17,11,9$, and 10 . The corresponding response rates for rats in Group TPH were $12,14,11,7$, and 8 . According to t-tests, there were no significant changes in response rates from pretest to Trial 1 of relearning (the reinstatement test) for rats in either group [ts(30) $<.73$, p $>.05$ ]. A 2 (groups) $\times 4$ (trials) analysis of variance indicated that there was a significant drop in response rates after Trial 1 in the relearning phase [Trials, 


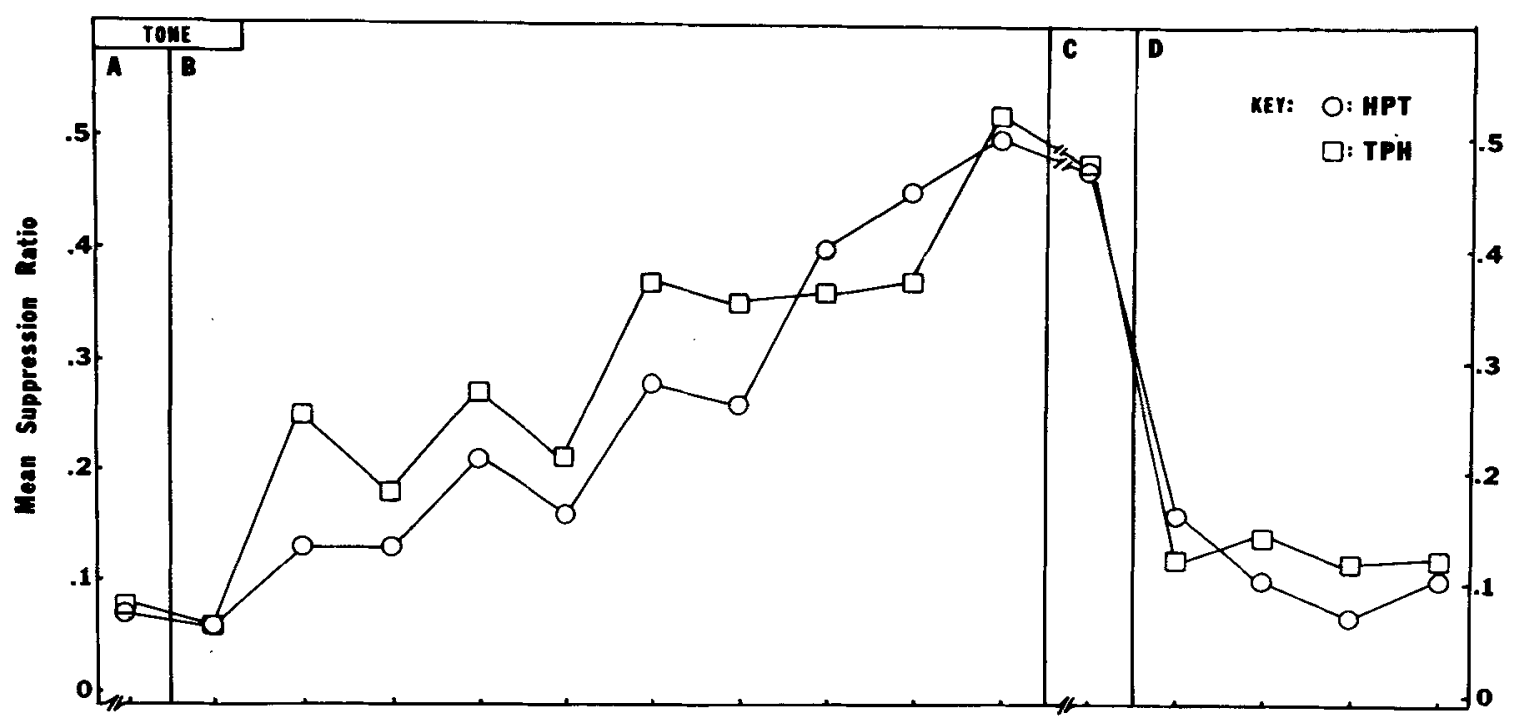

Trials

Figure 3. Mean suppression ratios during tone for rats in Group TPH (squares) and Group HPT (circles). Panel A represents the last day of conditioning, Panel B successive extinction trials, Panel $\mathbf{C}$ the last pretest trial, and Panel D the four test trials.

$F(3,90)=17.19, p<.05]$, but that there again was no difference among the groups' pretone response rates [groups, $\mathrm{F}(1,30)=.36, \mathrm{p}>.05$; groups $\times$ sessions, $F(3,90)=.17, p>.05]$.

\section{Discussion}

As in Experiment 2, extinction of fear during the tone was not significantly affected by prior extinctions with two other CSs. Unlike Experiment 2, however, the present experiment did obtain a reinstatement effect; apparently, delivery of four unsignaled shocks (Experiments 1 and 3 ) is sufficient to produce reinstatement, but delivery of two unsignaled shocks (Experiment 2) is not. Finally, order of extinction did not affect suppression during the reinstatement or relearning tests.

\section{GENERAL DISCUSSION}

Although there is an emerging consensus (e.g., Domjan \& Burkhard, 1982; Holland \& Rescorla, 1975; Wagner, 1981; Whitlow, 1976) that classical conditioning produces an associative connection between memorial representations of the $C S$ and US, there has been less concern with the underlying changes produced by extinction. Rescorla and his students (Rescorla \& Cunningham, 1978; Rescorla \& Heth, 1975) have suggested that such changes are basically the converse of those obtained in acquisition. That is, CS-only trials purportedly weaken the US representation and weaken the CS's associative strength. Two other suggestions were offered. First, change in potency of the US representation is supposed to occur more rapidly than change in associative strength. Second, the associative loss engendered by an extinction trial is supposed to be directly related to the strength of the US representation aroused on that trial.

The present research provided a rather direct test of these ideas. If extinction weakens the potency of the US representation, loss of the CR to one CS during extinction should be facilitated by prior extinction with other CSs. This outcome was not generally obtained: comparable changes in suppression ratios were found during extinction with a CS regardless of whether fear to it was extinguished first or last. There was also no evidence, in terms of either the magnitude of the reinstatement or rate of relearning, that a CS's associative strength could be protected from extinction by prior extinction with

Table 3

Mean Responses per Minute in Pretone Intervals During Each Extinction Trial

\begin{tabular}{ccccccccccc}
\hline $\begin{array}{c}\text { Trial/ } \\
\text { Group }\end{array}$ & 1 & 2 & 3 & 4 & 5 & 6 & 7 & 8 & 9 \\
\hline HPT & 14 & 14 & 14 & 12 & 18 & 14 & 17 & 13 & 16 & 10 \\
TPH & 11 & 9 & 11 & 9 & 12 & 10 & 10 & 8 & 11 \\
\hline
\end{tabular}


other CSs. Although it is impossible to prove the null hypothesis, it should be recalled that three experiments were conducted and that each successive experiment was designed to further increase the chances of obtaining an order-of-extinction effect. Furthermore, in an independently conducted series of experiments, Kasprow, Schactman, Cacheiro, and Miller (Note 1) also failed to obtain a decrement in the CR to one CS following extinction with another $\mathrm{CS}$.

One way to defend Rescorla's extinction theory against the present results would be to argue that the suppression ratios did not provide a reliable measure of the CR's strength during extinction or of the magnitude of associative loss during reinstatement and relearning tests. It might be argued that differences in the strength of the groups' CRs were obscured because the groups' baseline levels of responding were differentially sensitive to disruption. In fact, several recent studies (Hendry, 1982; Reberg, 1972) reported that an apparently extinguished CS, that is, one which produces little disruption when presented alone, can produce substantial suppression when paired with an excitatory CS of moderate strength. In other words, the amount of fear revealed seemed to depend on the amount of fear present when the CS was delivered. Regarding the present experiments, if the rats in each group had different amounts of fear conditioned to the contextual stimuli when the target CS was presented, their baseline response rates could have been differentially sensitive to the fear aroused by the CS. The present experiments probably should have provided several sessions of VI-only training after the conditioning phase to extinguish any fear that may have been conditioned to the context. As a rough measure of fear of the context, the present experiments examined pre-CS response rates, and no significant between-group differences were obtained during the extinction sessions with the target CS in Experiment 3 or during the early extinction sessions in Experiment 2. In any event, if different amounts of fear were elicited by the context during extinction with the target CS, it should have actually increased the chances of obtaining slower extinction for rats receiving extinction with the target CS first. This follows because greater contextual fear should have been present right after fear conditioning than after extinction sessions with nontarget CSs. Interestingly, the one instance in which a significant order-ofextinction effect was obtained (Experiment 1, tone CS) was also an instance in which a significant difference in pre-CS rates was obtained early in extinction.

In contrast to the results obtained by Kasprow et al. and the present authors, Rescorla and Cunningham (1977) found that the magnitude of a reinstated CR was reduced if it was preceded by an extinction trial with a nontarget CS. Although there are numerous procedural differences that could account for the discrepancy, a major factor may be that the Rescorla and Cunningham effect was a postreinstatement effect. Perhaps Rescorla's theory will be shown to apply only to the extinction of a CR that has been reinstated.

Finally, it should be noted that major support for the idea that extinction weakens the US representation comes from the demonstration of reinstatement. Although Rescorla interpreted the reinstatement effect as due to a restrengthening of the US representation, other interpretations are possible. For example, Bouton and Bolles (1979) present evidence which implies that reinstatement occurs because the additional shocks condition fear to the context and this provides a more sensitive baseline to detect residual fear to the CS. Interestingly, Bouton (1982) was unable to demonstrate reinstatement in a taste-aversion paradigm, where little contextual conditioning would be expected. In any event, it seems clear that more evidence is required before Rescorla's ideas on a degraded US representation can be accepted as a general account of extinction.

\section{REFERENCE NOTE}

1. Kasaprow, W. J., Schachtman, T. R., Cacheiro, H., \& Miller, R. R. Extinction does not depend upon degradation of event memories. Paper submitted for publication, 1983.

\section{REFERENCES}

Bouton, M. E. Lack of reinstatement of an extinguished taste aversion. Animal Learning \& Behavior, 1982, 10, 233-241.

Bouton, M. E., \& Bolles, R. C. Role of conditioned contextual stimuli in reinstatement of extinguished fear. Journal of Experimental Psychology: Animal Behavior Processes, 1979, 5, 368-378.

DOMJAN, M., \& BURKHARD, B. The principles of learning and behavior. Monterey, Calif: Brooks/Cole, 1982.

HENDRY, J. S. Summation of undetected excitation following extinction of the CER. Animal Learning \& Behavior, 1982, 10, 476-482.

Holland, P. C., \& Rescorla, R. A. The effect of two ways of devaluing the unconditioned stimulus after first- and secondorder appetitive conditioning. Journal of Experimental Psychology: Animal Behavior Processes, 1975, 1, 355-363.

REBERG, D. Compound tests for excitation in early acquisition and after prolonged extinction of conditioned suppression. Learning and Motivation, 1972, 3, 246-258.

Rescorla, R. A. A model of Pavlovian conditioning. In V. S. Rusinov (Ed.), Mechanisms of formation and inhibition of conditional reflex. Moscow: "Nauka" Academy of Sciences of the U.S.S.R., 1973. (a)

ReSCORLA, R. A. Effect of US habituation following conditioning. Journal of Comparative and Physiological Psychology, 1973, 82, 137-143. (b)

REsCorla, R. A. Effect of inflation of the unconditioned stimulus value following conditioning. Journal of Comparative and Physiological Psychology, 1974, 86, 101-106.

Rescorla, R. A. Some implications of a cognitive perspective on Pavlovian conditioning. In S. H. Hulse, H. Fowler, \& W. K. 
Honig (Eds.), Cognitive processes in animal behavior. Hillsdale, N.J: Erlbaum, 1978.

Rescorla, R. A., \& Cunningham, C. L. The erasure of reinstated fear. Animal Learning \& Behavior, 1977, 5, 386-394.

Resconla, R. A., \& Cunningham, C. L. Recovery of the US representation over time during extinction. Learning and Motivation, 1978, 9, 373-391.

Rescorla, R. A., \& Heth, C. D. Reinstatement of fear to an extinguished conditioned stimulus. Journal of Experimental Psychology: Animal Behavior Processes, 1975, 1, 88-96.

WAGNER, A. R. Priming in STM: An information-processing mechanism for self-generated or retrieval-generated depression in performance. In T. J. Tighe \& R. N. Leaton (Eds.), Habituation: Perspectives from child development, animal behavior, and neurophysiology. Hillsdale, N.J: Erlbaum, 1976.
WAgner, A. R. Expectancies and the priming of STM. In S. H. Hulse, H. Fowler, \& W. K. Honig (Eds.), Cognitive processes in animal behavior. Hillsdale, N.J: Erlbaum, 1978.

WAGNER, A. R. SOP: A model of automatic memory processing in animal behavior. In N. E. Spear \& R. R. Miller (Eds.), Information processing in animals: Memory mechanisms. Hillsdale, N.J: Erlbaum, 1981.

Whitlow, J. W., Jn. The dynamics of episodic processing in Pavlovian conditioning. In D. L. Medin, W. A. Roberts, \& R. T. Davis (Eds.), Processes of animal memory. Hillsdale, N.J: Erlbaum, 1976.

(Manuscript received December 27, 1982; revision accepted for publication February 11,1983 .) 